a second sample sent for LS analysis. The cause of the original effusion was agreed by two independent consultants after a minimum 12 month follow-up period.

Results 395 patients with undiagnosed effusions were seen, of which $124(31 \%)$ were found to be lymphocytic on initial examination. 35(28.2\%) patients were excluded due to confirmed (non-haematological) malignancy (11 initial cytology, 24 biopsy). A further 46(37.1\%) patients were excluded with confirmed benign diagnoses including inflammatory pleuritis, heart failure and pleural infection. 39/43 (90.7\%) patients therefore had samples sent for LS analysis.

$7 / 43(16.3 \%)$ patients' effusions were diagnosed at 12 months as primarily due to lymphoma, with 5 having a previous diagnosis of such. Their characteristics are described in the table below.

LS analysis was diagnostic in 4 and negative in 35 cases. There were no false positive results. Therefore, based on these data, for determining whether there is haematological malignancy in lymphocytic pleural fluid, LS analysis has a sensitivity of $57.1 \%$, a specificity of $100 \%$, and a positive and negative predictive value of $100 \%$ and $91.4 \%$ respectively.

Conclusions LS analysis appears useful in a selected subgroup of patients presenting with undiagnosed effusions. It should only be considered in those patients with a lymphocytic effusion which shows negative initial cytology and/or no firm diagnosis established on pleural biopsy, or those with a past medical history of a lymphoma. A negative LS result does not exclude the possibility of a haematological cause for the effusion.

\begin{tabular}{|c|c|c|c|c|c|c|}
\hline Patient & Disease & Comorbidities & $\begin{array}{l}\text { History of } \\
\text { lymphoma }\end{array}$ & $\begin{array}{l}\text { LS } \\
\text { positive }\end{array}$ & $\begin{array}{l}\text { Tissue } \\
\text { obtained }\end{array}$ & $\begin{array}{l}\text { Tissue } \\
\text { diagnostic? }\end{array}$ \\
\hline 1 & DLBCL & Nil & No & No & Marrow & Yes \\
\hline 2 & DLBCL & $\mathrm{AF}$ & Yes & Yes & Marrow & No \\
\hline 3 & DLBCL & $\mathrm{CCF}, \mathrm{AF}$ & Yes & No & Node & Yes \\
\hline 4 & $\begin{array}{l}\text { Low grade } \\
\mathrm{NHL}\end{array}$ & Nil & Yes & Yes & Too frail & \\
\hline 5 & $\begin{array}{l}\text { Low grade } \\
\text { NHL }\end{array}$ & Nil & Yes & No & Too frail & \\
\hline 6 & CLL & Nil & Yes & Yes & No & \\
\hline 7 & CLL & T2DM, AF & No & Yes & Thoracoscopy & Yes \\
\hline
\end{tabular}

\section{P210 DEFINING THE MINIMAL IMPORTANT DIFFERENCE FOR THE VISUAL ANALOGUE SCALE FOR DYSPNOEA IN PATIENTS WITH MALIGNANT PLEURAL EFFUSIONS}

${ }^{1}$ EK Mishra, ${ }^{1} \mathrm{~J}$ Corcoran, ${ }^{1} \mathrm{R}$ Hallifax, ${ }^{1} \mathrm{~J}$ Stradling, ${ }^{2} \mathrm{~N}$ Maskell, ${ }^{1} \mathrm{~N}$ Rahman; ${ }^{1}$ University of Oxford, Oxford, UK; ${ }^{2}$ University of Bristol, Bristol, UK

\subsection{6/thoraxjnl-2013-204457.362}

Background Malignant pleural effusions (MPEs) cause disabling dyspnoea in over 1 million people worldwide per year. Currently recruiting and recently reported randomised controlled trials (RCTs) use the visual analogue scale for dyspnoea (VASD) to assess mean daily breathlessness in patients with MPEs (ISRCTN12852177, ISRCTN4784593, ISRCTN73255764) in order to provide evidence for the optimal method of symptom palliation. The VASD consists of a $100 \mathrm{~mm}$ line which subjects mark at a point representing their dyspnoea intensity.
Determination of the minimal important difference (MID) for the VASD in patients with MPEs is essential to interpret the results of these trials.

Methods Patients with a confirmed or suspected MPE undergoing a pleural procedure recorded their baseline VASD prior to the procedure and, 24 hours later, their post-procedure VASD and assessed their dyspnoea on a 7 point Likert scale. Age, gender, diagnosis, procedure performed and volume of fluid drained were also recorded.

Results A total of 114/123 (93\%) questionnaires were returned. Mean age of respondents was 70 years and $56 \%$ were female. Commonest malignancies were breast (41\%), mesothelioma (26\%) and non-small cell lung cancer (18\%). Procedures included: therapeutic aspiration (35\%), medical thoracoscopy (27\%), chest drain insertion (11\%), diagnostic tap (11\%) and indwelling pleural catheter insertion (8.8\%). The mean decrease in VASD in patients reporting a 'small but just worthwhile decrease' in their dyspnoea (i.e. equivalent to the MID) was $19 \mathrm{~mm}$ (95\% CI 14-24 mm). The volume of fluid required to drain to produce a change in VASD of $19 \mathrm{~mm}$ was $760 \mathrm{ml}$. Mean decrease in VASD for the different procedures were: chest drain $41 \mathrm{~mm}$; IPC insertion and drainage $41 \mathrm{~mm}$; therapeutic aspiration $31 \mathrm{~mm}$; diagnostic aspiration $19 \mathrm{~mm}$; and LAT $24 \mathrm{~mm}$.

Conclusion The MID for the VASD in patients with a MPE undergoing a pleural procedure is $19 \mathrm{~mm}$ (95\% CI $14-24 \mathrm{~mm}$ ). This value should be used when interpreting the results of RCTs in patients with MPEs using the VASD as an outcome measure and to calculate the sample size for future RCTs.

\section{P211 DOMICILIARY CARE OF PATIENTS WITH PRIMARY AND SECONDARY PNEUMOTHORACES: OUR EXPERIENCE IN AYRSHIRE, PATIENT SATISFACTION AND HEALTH ECONOMIC ANALYSIS}

${ }^{1}$ A Guhan, 'S Learmonth, ${ }^{2} \mathrm{O}$ Moseley, ${ }^{1} \mathrm{D}$ Sword, ${ }^{1} \mathrm{~F}$ Kelly; ${ }^{1}$ University Hospital Ayr, NHS Ayrshire and Arran, Ayr, United Kingdom; ${ }^{2}$ NHS Ayrshire and Arran, Ayr, United Kingdom

\subsection{6/thoraxjnl-2013-204457.363}

Background Domiciliary care (DC) of Spontaneous Pneumothoraces (SP) with an ambulatory Heimlich Valve (HV) attached to the Intercostal Chest Drain (ICD) has potential for carecloser-to-home, avoiding hospitalisation and saving healthcare resources. Wider acceptance of this practice requires demonstration of tangible benefits in terms of patient safety, patient satisfaction and cost savings.

Method In the last year (since July 2012), we established a consultant-led DC service for SP at the University Hospital Ayr, Ayrshire. All primary (PSP) or secondary (SSP) SP admitted through The Emergency Department (ED) were assessed within 48 hours for potential DC with informed consent, based on presence of Persistent Air Leak and predetermined criteria ensuring patient safety (Table:1). All DC patients had 72 hourly consultant ward reviews (CWR) with chest Xray or sooner should patients identify HV non-movement with coughing. ICD was removed when SP resolved. SP patients on DC were readmitted if concerns were identified. Patient satisfaction was assessed formally (Table 6).

Health economics: Costs were calculated from an NHS perspective by examining resource use associated with DC for SP. This figure was then compared against the potential cost-avoidance in terms of respiratory medicine bed days saved. Costs were taken from published ISD reference costs when available and local 